\title{
Evaluation of fracture risk and potential drug holidays for postmenopausal women on long-term bisphosphonate therapy
}

This article was published in the following Dove Press journal:

International Journal of Women's Health

28 April 2014

Number of times this article has been viewed

\section{Matthew D Kostoff \\ Joseph J Saseen \\ Laura M Borgelt}

Departments of Clinical Pharmacy and Family Medicine, University of Colorado Skaggs School of Pharmacy and Pharmaceutical Sciences and School of Medicine, Aurora, CO, USA
Correspondence: Laura M Borgelt University of Colorado Anschutz Medical Campus (C238), Skaggs School of

Pharmacy and Pharmaceutical Sciences, I 2850 E Montview Blvd, V20-2I 24,

Aurora, CO 80045, USA

Tel +l 3037242650

Fax +I 3037240979

Email laura.borgelt@ucdenver.edu
Study objective: To describe characteristics of postmenopausal women on long-term bisphosphonate therapy who fall into one of four fracture risk categories (low, mild, moderate, high), and to determine the prevalence of women eligible for a drug holiday.

Design: Retrospective electronic health record review.

Setting: Eight primary care clinics within a university-based health care system.

Patients: A total of 201 postmenopausal women of ages 55-89 years, with osteopenia or osteoporosis, prescribed bisphosphonate therapy for $>4$ years, between October 10, 2002 and September 9, 2012.

Main results: The patients' mean age was $71.4( \pm 8.2)$ years; their mean body mass index was $25.3( \pm 5.6) \mathrm{kg} / \mathrm{m}^{2}$; and $73.1 \%$ were white. Seventy-four out of 201 patients $(36.8 \%)$ were lowrisk; 10/201 (5.0\%) were mild-risk; 72/201 (35.8\%) were moderate-risk; and 45/201 (22.4\%) were high-risk. Eighty-one women $(40.3 \%)$ were eligible for a drug holiday or discontinuation. The estimated drug cost avoided per eligible patient was $\$ 574.80$. Calcium and/or vitamin D supplementation was documented in $52.7 \%$ of women.

Conclusion: More than one-third of postmenopausal women taking long-term bisphosphonate therapy had low fracture risk, and over $40 \%$ of our patients were eligible for a drug holiday or discontinuation. These data emphasize the need to accurately assess risk and benefit in patients treated with bisphosphonate therapy.

Keywords: postmenopausal osteoporosis, bisphosphonates, drug holiday, fracture

\section{Introduction}

Bisphosphonates are widely prescribed for the prevention and treatment of osteoporosis. As the prescribing of these drugs has increased over the past decade, multiple concerns have arisen regarding adverse effects, including osteonecrosis of the jaw and esophageal cancer (though there have been conflicting data to support this association). ${ }^{1,2}$ The association of bisphosphonate therapy and atypical fracture continues to be a topic of investigation, with evidence demonstrating that longer duration of treatment is correlated with increased risk. ${ }^{3-5}$ Due to these potential adverse effects of bisphosphonate therapy, some experts have advocated for a period of time off therapy (or a "drug holiday") for certain patients. ${ }^{6}$ As a result, proper patient selection for a drug holiday and appropriate treatment duration and implementation of a drug holiday continue to be topics of uncertainty.

In September 2011, after the US Food and Drug Administration (FDA) evaluated the long-term efficacy and safety data for bisphosphonates, a recommendation was made to provide clarification, on the package insert labeling, about the duration of 
bisphosphonate therapy. ${ }^{7,8}$ However, the FDA committee could not come to a consensus regarding a specific recommendation. Consequently, the following statement is now listed on bisphosphonate package labeling: "The optimal duration of use has not been determined. The need for continued therapy should be re-evaluated on a periodic basis." In response to the FDA committee, the American Association of Clinical Endocrinologists recommends maintaining current practice with bisphosphonate therapy until the FDA comes to a final consensus on treatment duration. ${ }^{9}$ In the 2013 Clinician's Guide to Prevention and Treatment of Osteoporosis, the National Osteoporosis Foundation recognized that there is limited evidence to guide the duration of treatment. It stated that those at modest risk of fracture may have bisphosphonate therapy discontinued after 3-5 years, while continuation of treatment should be considered in those with high fracture risk. ${ }^{10}$

Based on expert opinion, the need for, and duration of a drug holiday are related both to treatment duration and to fracture risk. Diab and Watts suggested different drug holiday durations, based on assessment of patient-specific fracture risk (mild, moderate, or high). For those with mildly increased risk, the authors recommend treatment for approximately 5 years, with a drug holiday until bone mineral density (BMD) decreases significantly or fracture occurs. For those with moderately increased risk, the authors recommend treatment for 5-10 years, with a 2-3 year drug holiday. For high-risk patients, treatment for 10 years, followed by a 1-2 year drug holiday, was recommended. ${ }^{11}$ The definitions of what constituted mild, moderate, and high risk were not discussed.

To the best of our knowledge, there is no literature available that provides criteria for fracture risk categorization, or the percentage of patients who will typically fall into these risk categories and ultimately, be potential candidates for a drug holiday. The aims of this study were to describe the fracture risk of postmenopausal women on long-term bisphos- phonate therapy in primary care, identify postmenopausal women who could be potential candidates for a drug holiday or discontinuation, estimate potential drug cost avoidance, and describe documentation for calcium and vitamin D supplementation taken by postmenopausal women on longterm bisphosphonate therapy.

\section{Methods}

\section{Study design and patient population}

This retrospective, observational medical record review was approved by the Colorado Multiple Institutional Review Board. Electronic health records (EHRs) from eight primary care clinics within the University of Colorado Health system were screened to determine eligible patients. Included in the study were women aged 55-89 years old (or younger, with a diagnosis of postmenopause), who had at least 4 years of documented, continuous bisphosphonate therapy (alendronate, ibandronate, risedronate, or zoledronic acid), and with diagnoses of osteopenia or osteoporosis. Women were excluded if they received treatment with a bisphosphonate for an indication other than osteoporosis or osteopenia (eg, Paget's disease, hypercalcemia of malignancy).

\section{Primary and secondary outcomes}

The primary outcome of the study was to determine the prevalence of women in the four fracture risk categories (low, mild, moderate, and high), at the time of their last use of bisphosphonate, as documented in the EHR. Risk categorization was determined by the presence of osteoporosis or osteopenia and the number of risk factors for fracture at the date of last documented bisphosphonate use (Table 1). ${ }^{12}$ Women with a history of fragility fracture were placed in the high-risk category.

Secondary outcomes of the study included the prevalence of postmenopausal women with known treatment duration of bisphosphonates who may be eligible for a drug holiday, the estimated drug cost avoidance for

Table I Fracture risk categorization criteria, treatment duration, and drug holiday duration

\begin{tabular}{lllll}
\hline Risk category & Diagnosis & $\begin{array}{l}\text { Number of } \\
\text { risk factors }\end{array}$ & $\begin{array}{l}\text { Treatment } \\
\text { duration }\end{array}$ & Drug holiday \\
\hline Low & Osteopenia $^{\mathrm{b}}$ & $0-2$ & Not indicated & n/a \\
Mild & Osteopenia $^{\mathrm{b}}$ & 2 & 5 years & $\begin{array}{l}\text { Until fracture or significant } \\
\text { decrease in BMD } \\
\text { Moderate }\end{array}$ \\
High $^{d}$ & Osteoporosis $^{\mathrm{c}}$ & $0-2$ & $5-10$ years & $2-3$ years \\
\hline
\end{tabular}

Notes: ${ }^{\mathrm{a}} \mathrm{Age} \geq 70$ years old; corticosteroid use of $\geq 5 \mathrm{mg}$ prednisone or equivalent for $\geq 3$ months ever; $\geq 3$ alcohol drinks/day; low BMI (defined as $<18 \mathrm{~kg} / \mathrm{m}^{2}$ ); parental history of hip fracture; white or Asian race; secondary osteoporosis, rheumatoid arthritis; ${ }^{12}$ bdefined as most recent T-score between -1 and -2.5 ; ' ${ }^{\circ}$ defined as most recent T-score at or below -2.5 ; ${ }^{d}$ women with history of fragility fracture, categorized as high-risk.

Abbreviations: $\mathrm{n} / \mathrm{a}$, not applicable; BMD, bone mineral density; BMI, body mass index. 
postmenopausal women when eligible for a drug holiday, and determination of the rate of accurate documentation for calcium and vitamin $\mathrm{D}$ taken by postmenopausal women on long-term bisphosphonate therapy. Criteria for drug holidays, based on recommended duration of therapy, can be seen in Table 1. Low-risk patients were considered eligible for drug discontinuation because they were likely placed on bisphosphonate therapy inappropriately (ie, low-risk patients would not meet criteria for initiating treatment based on FRAX ${ }^{\circledR}$ scoring [the World Health Organization's fracture risk assessment tool]).

\section{Data collection and analysis}

Drug cost avoidance data were determined based on a monthly cost of alendronate $70 \mathrm{mg}$ weekly. ${ }^{13}$ Given that low-risk patients are candidates for drug discontinuation, all months of treatment in low-risk patients were considered for drug cost avoidance. For mild risk, any months of treatment beyond 5 years were considered for drug cost saving, and any months after 10 years were considered for moderate- and high-risk patients. Calcium and vitamin D documentation was determined by the presence of these supplements in the patient's medication list at the date of the last documented bisphosphonate prescription.

Data were extracted from the EHR, using the inclusion criteria as parameters, to produce a list of women to be evaluated. All women initially extracted from this list were verified for inclusion through individual patient reviews. International
Classification of Diseases, 9th Revision, Clinical Modification (ICD-9-CM) codes were used to identify patients with osteoporosis (code 733.0X). To identify osteopenic patients, "osteopenia" was searched in the patient's problem list within the EHR. These diagnoses were then confirmed using dualenergy X-ray absorptiometry (DXA) scan results, for each patient who met study criteria. Women without documentation of a DXA scan were not included in the analysis, because their diagnosis could not be verified. Exclusion criteria were evaluated on an individual patient basis, once the list was created. For generation of the initial report, women with $>2$ years of continuous therapy (rather than 4 years) were selected, to ensure that the greatest number of patients could be included.

Data were collected describing patient demographics, risk factors for fracture, bisphosphonate medication, duration, and indication, DXA scan results, and calcium and vitamin D supplementation. These data were analyzed using descriptive statistics, which included means with standard deviation (SD), frequencies (actual and percentage), and estimation of cost avoidance, where appropriate.

\section{Results}

There were 372 women who met age and diagnosis requirements and who had $>2$ years of bisphosphonate therapy. Of these, 147 women were excluded for having $<4$ years of continuous therapy, and 24 were excluded for having no DXA scan documented in their EHR. A total of 201 patients met all study criteria and were included in the

Table 2 Demographics

\begin{tabular}{|c|c|c|c|c|c|}
\hline & $\begin{array}{l}\text { Low-risk } \\
(n=74)\end{array}$ & $\begin{array}{l}\text { Mild-risk } \\
(n=\mid 0)\end{array}$ & $\begin{array}{l}\text { Moderate-risk } \\
(n=72)\end{array}$ & $\begin{array}{l}\text { High-risk } \\
(n=45)\end{array}$ & $\begin{array}{l}\text { Total } \\
(n=20 I)\end{array}$ \\
\hline \multicolumn{6}{|l|}{ Age } \\
\hline Mean $\pm S D$, (range) & $69.3 \pm 7.4(57-89)$ & $74.3 \pm 4.1(70-82)$ & $70.3 \pm 7.7(56-88)$ & $75.9 \pm 9.0(55-89)$ & $71.4 \pm 8.2(55-89)$ \\
\hline \multicolumn{6}{|l|}{$\mathrm{BMI}$} \\
\hline Mean $\pm S D$, (range) & $26.3 \pm 5.5(17.8-42.0)$ & $24.3 \pm 5.6(I 6 . I-34.3)$ & $24.2 \pm 4.7(17.1-39.3)$ & $25.6 \pm 6.9(14.3-46.8)$ & $25.3 \pm 5.6(14.3-46.8)$ \\
\hline \multicolumn{6}{|c|}{ Treatment duration (months) } \\
\hline Mean \pm SD, (range)* & $70.2 \pm 11.7$ (49-93) & $69.6 \pm 14.3(50-86)$ & $69.4 \pm 11.5$ (48-87) & $72.0 \pm 12.6(48-87)$ & $70.3 \pm 11.9(48-93)$ \\
\hline \multicolumn{6}{|l|}{ Race, n (\%) } \\
\hline Asian & $6(8.1)$ & $0(0)$ & $13(18.1)$ & $2(4.4)$ & $21(10.4)$ \\
\hline Black & $4(5.4)$ & $0(0)$ & $3(4.2)$ & I (2.2) & $8(4.0)$ \\
\hline White & $58(78.4)$ & $10(100)$ & $44(61.1)$ & $35(77.8)$ & $147(73.1)$ \\
\hline Other/unknown & $6(8.1)$ & $0(0)$ & $12(16.7)$ & $7(15.6)$ & $25(12.4)$ \\
\hline \multicolumn{6}{|l|}{ Medications, n (\%) } \\
\hline Alendronate & $48(64.9)$ & $9(90.0)$ & $47(65.3)$ & $30(66.7)$ & 134 (66.7) \\
\hline Ibandronate & $3(4 . I)$ & $0(0)$ & $0(0)$ & $3(6.7)$ & $6(3.0)$ \\
\hline Risedronate & $5(6.8)$ & I (I0.0) & $12(16.7)$ & $6(13.3)$ & $24(11.9)$ \\
\hline Zoledronic acid & $2(2.7)$ & $0(0)$ & $0(0)$ & $0(0)$ & $2(1.0)$ \\
\hline Two of the above & 14 (I8.9) & $0(0)$ & $13(18.1)$ & $6(13.3)$ & $33(16.4)$ \\
\hline Three of the above & $2(2.7)$ & $0(0)$ & $0(0)$ & $0(0)$ & $2(1.0)$ \\
\hline
\end{tabular}

Note: *The exact start date was unknown for 123/20I (61.2\%) of women.

Abbreviations: SD, standard deviation; BMI, body mass index. 
analysis. Demographic information is presented in Table 2. The mean age was 71.4 years. The mean duration of documented bisphosphonate therapy was 70.3 months. The mean age was highest in high-risk patients (75.9 years) and lowest in lowrisk patients (69.3 years). Most patients were white (73.1\%). The average body mass index was $25.3 \mathrm{~kg} / \mathrm{m}^{2}$. The majority of patients $(66.7 \%)$ were prescribed alendronate. The exact start date of bisphosphonate therapy was unknown for 123 of the 201 women $(61.2 \%)$. None of the women were prescribed more than one bisphosphonate at a time, but 35/201 (17.4\%) were prescribed more than one different bisphosphonate during their treatment period.

For the primary outcome of fracture risk categorization, 74/201 (36.8\%) were low-risk; 10/201 (5.0\%) were mild-risk; 72/201 (35.8\%) were moderate-risk; and 45/201 (22.4\%) were high-risk (Figure 1). No patients had 10 years of documented therapy. As a result, drug eligibility and discontinuation was only determined in the low- and mild-risk patients. Three of the 10 mild-risk patients did not qualify for a drug holiday due to having $<5$ years of treatment. Combining the 74 low-risk patients and 7 of 10 eligible mild-risk patients resulted in $81 / 201(40.3 \%)$ of the total population being eligible for a drug holiday or discontinuation (Table 3).

The 74 low-risk patients had a combined treatment duration of 5,198 months. The 7 mild-risk patients eligible for a drug holiday had a total 123 months of therapy beyond 5 years. This resulted in 5,321 months of therapy eligible for drug cost avoidance. A cost of $\$ 2.02$ for a $70 \mathrm{mg}$ alendronate tablet resulted in a total cost of $\$ 105.04$ for 52 weeks of treatment, which was converted to monthly cost of approxi-

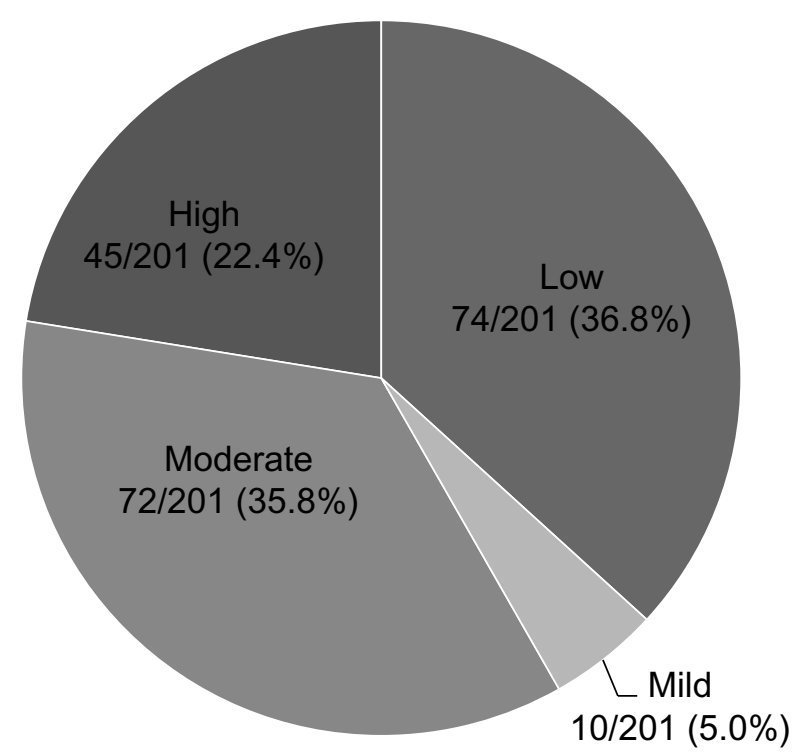

Figure I Primary outcome results: risk category (n, \%).
Table 3 Drug holiday eligibility and estimated drug cost avoidance

\begin{tabular}{llll}
\hline & $\begin{array}{l}\text { Low-risk } \\
(\mathbf{n}=\mathbf{7 4})\end{array}$ & $\begin{array}{l}\text { Mild-risk } \\
(\mathbf{n}=1 \mathbf{0})\end{array}$ & $\begin{array}{l}\text { Total (low and } \\
\text { mild) }(\mathbf{n}=\mathbf{8 4})\end{array}$ \\
\hline $\begin{array}{l}\text { Number of patients } \\
\text { eligible (\% of total }\end{array}$ & $74(36.8 \%)$ & $7(3.5 \%)$ & $81(40.3 \%)$ \\
$\begin{array}{l}\text { population) } \\
\text { Cumulative number of } \\
\text { treatment months eligible } \\
\text { for drug cost avoidance }\end{array}$ & 5,198 & 123 & 5,321 \\
$\begin{array}{l}\text { Estimated drug cost } \\
\text { avoidance }\end{array}$ & $\$ 45,482.50$ & $\$ 1,076.25$ & $\$ 46,558.75$ \\
$\begin{array}{l}\text { Estimated drug cost } \\
\text { avoidance/patient }\end{array}$ & $\$ 6 \mid 4.63$ & $\$ 153.75$ & $\$ 574.80$ \\
\hline
\end{tabular}

mately $\$ 8.75 .^{13}$ Multiplying 5,321 eligible months by the $\$ 8.75$ monthly cost of alendronate gave a total cost avoidance of $\$ 46,558.75$, or $\$ 574.80$ per eligible woman (Table 3).

Documentation of both calcium and vitamin D supplementation was noted for 106/201 (52.7\%) of the total population (Table 4). Calcium only was documented in 10/201 (5.0\%) of women; vitamin D only was documented in 30/201 (14.9\%); neither supplement was documented in $55 / 201(27.4 \%)$ of women. Although it was not established a priori, the time between date of last documented bisphosphonate use and most recent DXA scan was evaluated. Of the total population, 56/201 (27.9\%) had $>24$ months elapsed without a DXA scan, and 45/201 (22.4\%) had >30 months elapsed since their last DXA scan.

\section{Discussion}

This study revealed that patient-specific fracture risk evaluation could be performed to identify patients as low-, mild-, moderate-, or high-risk. Based on expert opinion and previously published studies, we established criteria for low, mild, moderate, and high fracture risk. We believe these criteria accurately reflect fracture risk in the postmenopausal population, and are generalizable. More than one-third of the patient population was considered low-risk for fracture. It was found that $40.3 \%$ of women may be eligible for a drug holiday or drug discontinuation. This analysis provided a description of postmenopausal women on long-term bisphosphonate therapy, which has not been previously available in current literature.

Due to a change in the EHR system at the study institution, medical record data prior to 2005 were not available. This is the main reason for exact start dates of bisphosphonate therapy being unknown in 123/201 (61.2\%) of women. Additionally, any woman who entered the system after 2005 , while already on bisphosphonate therapy, did not have a start date clearly identified. As a result, the potential for a drug 
Table 4 Calcium and vitamin D documentation

\begin{tabular}{|c|c|c|c|c|c|}
\hline $\begin{array}{l}\text { Supplement } \\
\text { documentation }\end{array}$ & $\begin{array}{l}\text { Low-risk }(n=74) \\
\text { n (\%) }\end{array}$ & $\begin{array}{l}\text { Mild-risk }(n=10) \\
n(\%)\end{array}$ & $\begin{array}{l}\text { Moderate-risk }(n=72) \\
n(\%)\end{array}$ & $\begin{array}{l}\text { High-risk (n=45) } \\
\text { n (\%) }\end{array}$ & $\begin{array}{l}\text { Total }(n=20 I) \\
n(\%)\end{array}$ \\
\hline Calcium only & $2(2.7)$ & $2(20.0)$ & $3(4.2)$ & $3(6.7)$ & $10(5.0)$ \\
\hline Vitamin D only & $13(17.6)$ & I (I0.0) & $10(13.9)$ & $6(13.3)$ & $30(14.9)$ \\
\hline Calcium and vitamin D & $33(44.6)$ & $6(60.0)$ & $43(59.7)$ & $24(53.3)$ & $106(52.7)$ \\
\hline Neither & $26(35.1)$ & $I(I 0.0)$ & $16(22.2)$ & $12(26.7)$ & $55(27.4)$ \\
\hline
\end{tabular}

holiday was not evaluated in the moderate- and high-risk groups, because 10 years of data were not available. Overall, the duration of therapy is likely to be an underestimation. It is most reasonable to assume that known start dates would have extended the average treatment duration of this patient population. It is likely this would result in more patients being eligible for drug holidays, and in greater potential drug cost avoidance.

While some patients were on brand name bisphosphonates, estimated drug cost avoidance was determined using generic alendronate, as the most conservative approach. Approximately $\$ 46,000$ in drug cost avoidance was estimated in the 201 patients included in this study. One study estimated that approximately 34.5 million Americans have osteopenia and another estimated that $49 \%$ of adults $>50$ years old in the USA have low bone mass at the lumbar spine or femoral neck. ${ }^{14,15}$ Consequently, it is possible that application of this analysis nationwide has the potential to result in significant drug cost avoidance.

Calcium and vitamin D supplementation was documented in approximately half of the total population. Recent studies have reported documentation rates of $16 \%-91 \%$ for patients taking bisphosphonates. ${ }^{16,17}$ Although the rates in this analysis may be an underestimation of true calcium and vitamin D use in this population, due to possible incomplete medication lists in the EHR, they suggest suboptimal supplementation use. Considering the importance of these supplements to bone health, prescribing and documentation would ideally occur in a larger percentage of women.

The general recommendation for frequency of DXA scans in this postmenopausal population is every 2 years, though more frequent testing could be done in certain situations and/or high-risk patients. ${ }^{18}$ The cutoff of $>30$ months since last DXA was also evaluated, as it may not be reasonable for a DXA scan to be done exactly every 2 years. Serial BMD measurements are of importance in this population, as testing can monitor response as well as guide the need for reassessment of treatment.

Additional limitations of this study are its setting in one health care system and its retrospective design. The use of only eight primary care clinics limited the number of patients included in the study. Retrospective analysis relies on accurate documentation. Information relating to risk factors (eg, parental hip fracture) may not be known or documented in an appropriate manner to collect during chart review. Additionally, clinical judgment was used to determine if a fracture was due to fragility, in situations where documentation was unclear.

This analysis was also performed under the assumption that medication reconciliation is being conducted at every office visit to assure accuracy of medication lists. Therefore, it was also assumed that each woman was taking a medication if it was prescribed and listed on her medication list. Unfortunately, this data collection could not be tied to a claims database, which could verify medication adherence.

The risk factors used in this analysis are similar to those used for the FRAX fracture risk assessment tool. ${ }^{19}$ It would not be very likely for a low-risk patient (eg, osteopenia with 0-2 risk factors) to qualify for treatment by the FRAX calculation. However, the FRAX calculation was not used in this analysis, as its use is not validated in patients currently receiving treatment. Since risk factors must be present in a "yes or no" manner, a specific age cutoff had to be used for the risk factor of elderly age. The authors of this study felt that available literature supported the use of 70 years of age as a cutoff for increased risk of fracture. ${ }^{20}$ A potential limitation, although unlikely, is that an elderly, low-risk woman could meet appropriate treatment criteria by the FRAX calculation, with age alone driving their increased risk for fracture.

\section{Conclusion}

This analysis highlights the need to accurately assess patientspecific risk factors prior to initiation of therapy, to determine fracture risk. Our novel approach clearly establishes criteria for low, mild, moderate, and high fracture risk. This assessment has the potential to identify overuse of bisphosphonates, by identifying a large proportion of women at low risk of fracture. This could result in a significant drug cost avoidance for patients on long-term bisphosphonate therapy. It also allows for appropriate assessment of patients who may need to remain 
on therapy, and who require a longer duration of treatment. Lastly, this analysis highlights suboptimal use of calcium and vitamin D, and frequency of DXA scans, which need to be accurately documented in the patient health care record.

\section{Disclosure}

The authors have no conflicts of interest to declare.

\section{References}

1. Khosla S, Burr D, Cauley J, et al. Bisphosphonate-associated osteonecrosis of the jaw: report of a task force of the American Society for Bone and Mineral Research. J Bone Miner Res. 2007;22:1479-1491.

2. Cardwell CR, Abnet CC, Cantwell MM, Murray LJ. Exposure to oral bisphosphonates and risk of esophageal cancer. JAMA. 2010;304: 657-663.

3. Shane E, Burr D, Ebeling PR, et al. Atypical subtrochanteric and diaphyseal femoral fractures: report of a task force of the American Society for Bone and Mineral Research. J Bone Miner Res. 2010;25:2267-2294.

4. Park-Wyllie LY, Mamdani MM, Juurlink DN, et al. Bisphosphonate use and the risk of subtrochanteric or femoral shaft fractures in older women. JAMA. 2011;305:783-789.

5. Meier RP, Perneger TV, Stern R, Rizzoli R, Peter RE. Increasing occurrence of atypical femoral fractures associated with bisphosphonate use. Arch Intern Med. 2012;172:930-936.

6. Watts NB, Bilezikian JP, Camacho PM, et al. American Association of Clinical Endocrinologists Medical Guidelines for Clinical Practice for the diagnosis and treatment of postmenopausal osteoporosis. Endocr Pract. 2010;16 Suppl 3:1-37.

7. US Food and Drug Administration. Summary minutes of the joint meeting of the Advisory Committee for Reproductive Health Drugs and Drug Safety and Risk Management Advisory Committee. September 9, 2011 [cited October 8, 2013]. Available from: http://www.fda.gov/downloads/ AdvisoryCommittees/CommitteesMeetingMaterials/Drugs/Reproductiv eHealthDrugsAdvisoryCommittee/UCM278481.pdf. Accessed January 27, 2014.

8. Whitaker M, Guo J, Kehoe T, Benson G. Bisphosphonates for osteoporosis - where do we go from here? N Engl J Med. 2012;366:2048-2051.
9. American Association of Clinical Endocrinologists. AACE Responds to FDA Hearing on Bisphosphonates. [cited October 8, 2013]. Available from: http://media.aace.com/press-release/aace-responds-fda-hearingbisphosphonates. Accessed January 27, 2014.

10. National Osteoporosis Foundation. Clinician's Guide to Prevention and Treatment of Osteoporosis. Washington, DC: National Osteoporosis Foundation; 2013.

11. Diab DL, Watts NB. Bisphosphonates in the treatment of osteoporosis. Endocrinol Metab Clin North Am. 2012;41:487-506.

12. Kanis JA. World Health Organization Scientific Group. Assessment of Osteoporosis at the Primary Health-Care Level. Technical report of the World Health Organization Collaborating Centre for Metabolic Bone Diseases. Sheffield, UK: University of Sheffield; 2007.

13. IMS National Prescription Audit, Feb 2013.

14. Looker AC, Melton LJ 3rd, Harris TB, Borrud LG, Shepherd JA. Prevalence and trends in low femur bone density among older US adults: NHANES 2005-2006 compared with NHANES III. J Bone Miner Res. 2010;25:64-71.

15. Looker AC, Borrud LG, Dawson-Hughes B, Shepherd JA, Wright NC. Osteoporosis or low bone mass at the femur neck or lumbar spine in older adults: United States, 2005-2008. NCHS Data Brief. 2012;93: $1-8$.

16. Rianon N, Anand D, Rasu R. Changing trends in osteoporosis care from specialty to primary care physicians. Curr Med Res Opin. 2013;29: 881-888.

17. Nye AM, Hamrick I, Rauch A, Pound MW, Shelton PS. Documenting the use of calcium supplements with oral bisphosphonates. Consult Pharm. 2013;28:31-38.

18. International Society of clinical Densitometry. 2007 ISCD Official Positions - Adult. [cited October 8, 2013]. Available from: http://www. iscd.org/official-positions/2007-iscd-official-positions-adult.

19. Kanis JA, Johnell O, Oden A, Johansson H, McCloskey E. FRAX and the assessment of fracture probability in men and women from the UK. Osteoporos Int. 2008;19:385-397.

20. Snelling AM, Crespo CJ, Schaeffer M, Smith S, Walbourn L. Modifiable and nonmodifiable factors associated with osteoporosis in postmenopausal women: results from the Third National Health and Nutrition Examination Survey, 1988-1994. J Womens Health Gend Based Med. 2001;10:57-65.
International Journal of Women's Health

\section{Publish your work in this journal}

The International Journal of Women's Health is an international, peerreviewed open-access journal publishing original research, reports, editorials, reviews and commentaries on all aspects of women's healthcare including gynecology, obstetrics, and breast cancer. The manuscript management system is completely online and includes

\section{Dovepress}

a very quick and fair peer-review system, which is all easy to use. Visit http://www.dovepress.com/testimonials.php to read real quotes from published authors. 